\title{
Bile acid-induced tissue factor activity in hepatocytes correlates with activation of farnesoid $\mathrm{X}$ receptor
}

Theresa Greimel ${ }^{1}$, Jörg Jahnel ${ }^{1}$, Sina Pohl ${ }^{1}$, Tanja Strini ${ }^{1}$, Martin Tischitz ${ }^{1}$, Nathalie Meier-Allard ${ }^{2}$, Sandra Holasek ${ }^{2}$, Katharina Meinel ${ }^{1}$, Victor Aguiriano-Moser ${ }^{1}$, Joachim Zobel ${ }^{1}$, Harald Haidl ${ }^{1}$, Siegfried Gallistl ${ }^{1}$, Katrin Panzitt ${ }^{3}$, Martin Wagner ${ }^{3}$ and Axel Schlagenhauf ${ }^{1 \times}$

(c) The Author(s), under exclusive licence to United States and Canadian Academy of Pathology 2021

Bile acids (BA) have been found to promote coagulation by increasing tissue factor (TF) activity. The contribution of elevated BA levels and cholestasis to TF decryption within the liver parenchyma and the role of farnesoid X receptor (FXR) in this process remain unclear. We investigated the effects of BA on TF activity and thrombin generation in hepatocytes and correlated these effects with activation of FXR-dependent signaling and apoptosis. HepG2 cells and primary hepatocytes were incubated with chenodeoxycholic acid (CDCA), glycochenodeoxycholic acid (GCDCA), ursodeoxycholic acid (UCDA), or the synthetic FXR agonist GW4064 for $24 \mathrm{~h}$. MTT tests demonstrated cell viability throughout experiments. TF activity was tested via factor Xa generation and thrombin generation was measured by calibrated automated thrombography. Increased TF activity alongside enhanced thrombin generation was observed with CDCA and GW4064 but not with GCDCA and UDCA. TF activity was substantially reduced when FXR activation was blocked with the antagonist DY 268. Quantitative polymerase chain reaction revealed upregulation of FXR target genes only by CDCA and GW4064. Western blot analysis and fluorescence microscopy showed no TF overexpression arguing for TF decryption. Caspase 3 activity measurements and flow cytometric analysis of Annexin $V$ binding showed no signs of apoptosis. Long-term exposure of hepatocytes to nontoxic BA may cause intracellular FXR overstimulation, triggering TF decryption irrespective of the amphiphilic properties of BA. The effect of BA on TF activation correlates with the molecule's ability to enter the cells and activate FXR. TF decryption occurs independently of apoptotic mechanisms.

Laboratory Investigation (2021) 101:1394-1402; https://doi.org/10.1038/s41374-021-00628-z

\section{INTRODUCTION}

Bile acids (BA) exhibit multiple metabolical functions apart from their well-known role in digestion and absorption of dietary lipids. They have been shown to regulate lipid, vitamin A, glucose, and glucocorticoid metabolism [1-4]. In humans, primary BA (cholic acid and chenodeoxycholic acid [CDCA]) are synthesized in the liver from cholesterol, whereas secondary BA (deoxycholic acid, lithocholic acid, and ursodeoxycholic acid [UDCA]) is metabolized in the colon [5]. BA self-regulates their synthesis and transport within the enterohepatic circulation via activation of the nuclear $B A$ receptor farnesoid $X$ receptor (FXR). FXR is a transcription factor expressed at high levels in hepatocytes and intestinal epithelial cells. Upon ligand activation, FXR binds to specific target genes and alters gene expression [6, 7]. Well-established FXR target genes include $N R O B 2$, encoding short heterodimer partner-1 (SHP), which reduces $B A$ synthesis by downregulation of CYP7A1 expression, and SLC51A and SLC51B, respectively encoding the ileal basolateral $B A$ transporters organic solute transporter alpha and beta (OST- $a$ and OST- $\beta$ ). Alterations in bile acid metabolism or secretion can cause cholestasis, resulting in hepatocellular or bile duct injury and chronic inflammation. Under such pathological conditions, sinusoidal endothelial cells foster liver fibrosis via enhanced angiogenesis and activation of hepatic stellate cells, processes implicated in cholestatic disorders such as primary biliary cholangitis and primary sclerosing cholangitis $[8,9]$. The impaired function of FXR has been shown to contribute to these diseases. Therefore, activation of FXR is a therapeutic goal for distinct cholestatic and non-cholestatic liver diseases $[10,11]$.

Besides their other functions, BA exerts procoagulant activity. In vitro, they directly enhance activation of the coagulation factor $X$ by interacting with a complex of recombinant tissue factor (TF) and activated factor VII [12]. Coagulation also plays a role in chronic liver injury; the fenestrated sinusoidal endothelial cells allow plasma flow from sinusoidal blood into the space of Disse [8], thereby granting contact of clotting factors with hepatocytes and cholangiocytes and facilitating local hemostatic action. Several studies demonstrate the role of hepatic coagulation activation in the pathology of liver fibrosis [13-15]. The key enzyme of coagulation is thrombin, which is generated by hepatocytes in a cholestatic setting in vivo and converts fibrinogen leading to fibrin deposits within the liver parenchyma [16]. However, the predominant mechanism of thrombin-induced liver injury is caused by protease-activated receptors (PARs) on neutrophils and hepatic stellate cells which mediate neutrophil activation and induction of profibrotic mediators $[15,17]$.

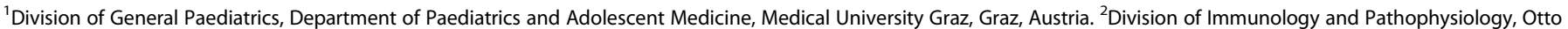

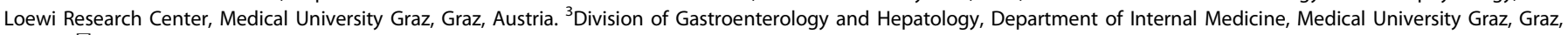
Austria. ${ }^{凶}$ email: axel.schlagenhauf@medunigraz.at

Received: 16 March 2021 Revised: 20 May 2021 Accepted: 4 June 2021

Published online: 18 June 2021 
Thrombin generation by hepatocytes is TF-dependent. TF, encoded by $F 3$, is a transmembrane glycoprotein expressed on hepatocytes. TF in complex with activated factor VII (FVIla) activates factor $X(F X)$, which leads to thrombin generation and fibrin formation [18, 19]. TF-induced thrombin generation can result in PAR-1- and PAR-4-mediated platelet activation [20]. Under physiological conditions, TF is present in hepatocytes in a non-activated, encrypted form [21]. The mechanism of TF decryption in cholestasis is still unknown in vivo. Studies investigating specifics of TF decryption are not feasible in vivo, because biopsy of hepatic tissue or homogenization of harvested livers from animal models compromises the microenvironment that surrounds TF leading to conformational alterations.

The general hypothesis is that TF activation results from alterations in plasma membrane phospholipid composition, possibly due to apoptotic mechanisms, that entrain conformational changes of the TF/FVIla complex, facilitating recognition of its substrate FX [18]. Alternatively, tissue factor decryption can occur via oxidation of Cys $186 / 209$ by an increase in protein disulfide isomerase on the plasma membrane [22]. Baker et al. investigated TF activation by BA using primary mouse hepatocytes [12]. They found an increase of TF-activation after 15 min but did not attribute it to BA-mediated intracellular signaling, since they did not observe this effect after incubation with the synthetic FXR-agonist GW4064 for $30 \mathrm{~min}$. Instead, they proposed another mechanism: the BA glycochenodeoxycholic acid (GCDCA) and taurochenodeoxycholic acid directly accelerate TF/ FVIla activity by acting as cofactors. However, this in vitro effect was only observable in the absence of phosphatidylserine with relipitated TF that was not encrypted via reduction of Cys $186 / 209$.

We hypothesized that an increase of TF activity in the liver parenchyma is not an acute phase reaction caused by a temporary increase in BA concentration but secondary to long-term overstimulation of BA-specific signaling pathways. Variations in BA concentrations are physiologically occurring during feeding/ fasting cycles without triggering thrombin generation. An acute BA surge is usually self-limiting by FXR regulation rendering an increase in TF activity within minutes counterproductive for hepatic function under physiological conditions. However, prolonged exposure of hepatocytes to high BA concentrations, which occurs in cholestatic liver injury, may trigger a cell danger response leading to TF decryption. Specific BA seems to differ in their potential to induce TF activation in hepatocytes, depending on their hydrophobicity, concentration, and conjugation. We hence sought to examine the effects of long-term exposure to different BA on cellular procoagulant activity and to correlate these effects with activation of FXR- dependent signaling in hepatocytes.

\section{MATERIALS AND METHODS \\ Cell culture}

HepG2 cells (source: cell culture core facility, Zentrum für Medizinische Forschung, Medizinische Universität Graz) (Center for Medical Research, Medical University of Graz; cells originally derived from CLS Cell Lines Service, Eppelheim, Germany, and Short Tandem Repeat-verified before usage) were cultured in Dulbecco's modified Eagle's medium (DMEM, GIBCO, Thermo Fisher Scientific, Waltham, MA), supplemented with $10 \%$ fetal bovine serum (GIBCO) and $1 \%$ penicillin-streptomycin (GIBCO) at $37^{\circ} \mathrm{C}$ and $5 \% \mathrm{CO}_{2}$. The split ratio was $1: 4$ to $1: 6$ every $3-4$ days. Plateable primary human hepatocytes from three different donors for confirmation experiments as well as thawing, plating, and maintenance medium were obtained from Lonza (Walkersville, MD). Cryopreserved cells were thawed for 90-120s, transferred into a thawing medium, centrifuged, and then transferred into a plating medium. Viability and yield were determined using the Trypan blue exclusion method. Cells were brought to a concentration of $1 \times 106$ cells $/ \mathrm{ml}$ and seeded into 24-well plates coated with collagen $\left(0.5 \times 106\right.$ cells/well). Cells were incubated overnight $\left(37^{\circ} \mathrm{C}\right.$,
$5 \%\left(\mathrm{CO}_{2}\right)$, and the plating medium was replaced by a maintenance medium.

\section{Cell treatment}

BA and GW4064 were purchased from Sigma (St. Louis, MO). HepG2 cells were treated with concentrations of CDCA, GCDCA, and UDCA ranging from 100 to $600 \mu \mathrm{M}$ and with concentrations of GW4064 ranging from 1 to $40 \mu \mathrm{M}$ and were incubated at $37^{\circ} \mathrm{C}$ for $12 \mathrm{~h}, 24 \mathrm{~h}, 48 \mathrm{~h}$, and $72 \mathrm{~h}$. Experiments with CDCA and GW4064 were repeated in presence of the potent FXR antagonist DY $268(10 \mu \mathrm{M})$ purchased from Axon Medchem (Groningen NL). Primary human hepatocytes were exposed to CDCA or GCDCA in concentrations ranging from 100 to $400 \mu \mathrm{M}$ for $24 \mathrm{~h}$. Dimethyl sulfoxide (DMSO) was used as a vehicle. After incubation, BA was removed from the cells before measurement of TF activity and thrombin generation. HepG2 cell viability was assessed via a commercial 3-[4,5-dimethylthiazole2-yl]-2,5-diphenyltetrazolium bromide (MTT) metabolic activity assay (ATCC Bioproducts, Manassas, VA). Cytotoxicity was assessed via the release of lactate dehydrogenase (LDH) using a commercial LDHCytotoxicity Assay Kit (Abcam, Cambridge, UK). All measurements were performed in duplicates from three independent experimental replicates $(N=6)$.

\section{TF activity assay}

TF activity was tested via FXa generation. Factor X (human; $150 \mathrm{nM}$, CoaChrom Diagnostica, Maria Enzersdorf, Austria), HBSA buffer $(137 \mathrm{mM}$ $\mathrm{NaCl}, 538 \mathrm{mM} \mathrm{KCl}, 555 \mathrm{mM}$ glucose, $10 \mathrm{mM}$ 4-[2-hydroxyethyl]-1-piperazineethanesulfonic acid (HEPES, Sigma), 0.1\% bovine serum albumin (BSA, Sigma), calcium chloride $(5 \mathrm{mM})$, and Factor Vlla (Novoseven; $100 \mathrm{U} / \mathrm{ml}$, Novo Nordisk, Vienna, Austria)) were added to adherent HepG2 cells or primary human hepatocytes pre-incubated with BA. After 15 min incubation, ethylene diamine tetraacetic acid ( $5 \mathrm{mM}$; Sigma) was added to stop the reaction. Generated factor Xa was detected using a chromogenic substrate (Perfachrome FXa 8595; 0.667 mM, Enzyme Research Labs, South Bend, IN) on a plate reader (Thermo Fisher Scientific), identifying the absorbance increase at $405 \mathrm{nM}$ for $60 \mathrm{~min}$ (average slope). Factor Xa concentrations were calculated via calibration with FXa. All measurements were performed in duplicates from three independent experimental replicates.

\section{Assessment of thrombin generation}

Thrombin generation was measured via calibrated automated thrombography (CAT) as reported [23] but without adding exogenous tissue factors. HepG2 cells were seeded in uncoated 96-well plates (Immulon 2HB, Thermo Fisher Scientific) and incubated with individual BA for $24 \mathrm{~h}$. After removal of $B A$, in-house pooled plasma standard and corn trypsin inhibitor $(0.1 \mathrm{mg} / \mathrm{ml})$ to prevent contact activation were added. Cell-derived TF was thus the sole trigger for thrombin generation. Fluobuffer for monitoring thrombin generation curves contained $20 \mathrm{mM}$ HEPES buffer (Thermo Fisher Scientific) and $60 \mathrm{mg} / \mathrm{ml}$ bovine serum albumin (Carl Roth, Karlsruhe, Germany) and was mixed with $1 \mathrm{M}$ calcium chloride solution (Merck, Darmstadt, Germany). Working buffer consisted of $140 \mathrm{mM} \mathrm{NaCl}$ (Merck), $20 \mathrm{mM}$ HEPES buffer, and $5 \mathrm{mg} / \mathrm{ml}$ human serum albumin (Sigma). The fluorogenic substrate Z-Gly-Gly-Arg-amino-methyl-coumarin (Bachem, Bubendorf, Switzerland) was dissolved in DMSO. The thrombin calibrator was purchased from Thrombinoscope BV (Maastricht, The Netherlands). The ability of a sample to generate thrombin was evaluated with respect to the total amount of thrombin activity (endogenous thrombin potential, ETP), which was assessed as the area under the curve and the time preceding the thrombin burst (lag time). All measurements were performed in triplicates from three independent experimental replicates.

\section{Western blot analysis of TF protein levels}

HepG2 cells were preincubated with BA for $24 \mathrm{~h}$ as mentioned above. The cells were then lysed in a buffer containing $50 \mathrm{mM}$ HEPES (Sigma), $150 \mathrm{mM}$ $\mathrm{NaCl}, 10 \%$ glycerol, and 1\% Triton X-100 (Sigma), pH 7.4 (lysis buffer). Halt Protease and Phosphatase Inhibitor Cocktail (Thermo Fisher Scientific) was added to the buffer $(1: 100)$. Cells were then scraped off, centrifuged, and supernatants were frozen at $-80^{\circ} \mathrm{C}$. In total, $10 \mu \mathrm{g}$ of protein were resolved by sodium dodecyl sulfate-polyacrylamide gel electrophoresis and blotted onto nitrocellulose membranes (Invitrogen, Thermo Fisher Scientific), followed by immunodetection with anti-tissue factor antibody (ab228968, Abcam, Cambridge, UK) and a mouse anti-rabbit IgG-HRP antibody 
(sc-2357, Santa Cruz Biotechnology, Dallas, TX). GAPDH served as loading and staining control. Blot bands were detected with a Molecular Imager Chemi DocTM XRST Imaging System (Bio-Rad). Densitometric analysis was performed with three independent experimental replicates.

\section{Caspase activity assay}

HepG2 cells were preincubated with BA or GW4064 for $24 \mathrm{~h}$ as mentioned above. For positive control, cells were incubated with $2 \mu \mathrm{M}$ and $4 \mu \mathrm{M}$ staurosporine for $24 \mathrm{~h}$. Cells were lysed and subjected to caspase activity measurements using a commercial Caspase 3 Assay Kit (Sigma). This 96 well plate assay is based on the hydrolysis of the peptide substrate acetylAsp-Glu-Val- Asp p-nitroanilide (Ac-DEVD-pNA) by caspase 3, resulting in the release of the $p$-nitroaniline (pNA) moiety. Cell lysates were mixed with assay buffer and the chromogenic substrate. Mixtures were incubated (10 $\mathrm{h}, 37^{\circ} \mathrm{C}$ ), and release of pNA was detected at $405 \mathrm{~nm}$ and quantified using a pNA calibration curve. Negative controls were obtained for each sample by the addition of a Caspase 3 inhibitor (Ac-DEVD-CHO).

\section{Quantitative polymerase chain reaction (qPCR)}

HepG2 cells were incubated with the above concentrations of BA for $12 \mathrm{~h}$ or $24 \mathrm{~h}$ and then dissolved in Buffer RLT (QIAGEN, Hilden, Germany). Cells treated with only DMSO for $12 \mathrm{~h}$ or $24 \mathrm{~h}$ served as controls. RNA was extracted via RNeasy Mini Kit (QIAGEN) according to the manufacturer's instructions and RNA concentration was determined using a DS-11 spectrophotometer (DeNovix, Wilmington, DE). RNA was transcribed to cDNA via Applied Biosystems High-Capacity RNA to cDNA Kit (Thermo Fisher Scientific) according to manufacturer's instructions. CDNA was synthesized in a C1000 Touch Thermal Cycler (CFX96 Real-Time System) (Bio-Rad, Hercules, CA) set for $10 \mathrm{~min}, 25^{\circ} \mathrm{C}-120 \mathrm{~min}, 37^{\circ} \mathrm{C}-5 \mathrm{~min}, 85^{\circ}$ $\mathrm{C}-\infty, 8^{\circ} \mathrm{C}$. Relative expression of FXR-target genes NROB2, SLC51A, $S L C 51 B$, and $F 3$, encoding SHP, OST- $a$, OST- $\beta$, and TF were analyzed using $A C T B$, encoding $B$-actin, as reference. Reactions were performed in triplicate on 96-well plates. The primers used were: ACTB, Human (BioRad Unique Assay ID: qHsaCED0036269); F3, Human (Bio-Rad Unique Assay ID: qHsaCED0036452); NROB2 (Bio-Rad, Custom Primer Pair Desalt 200R, fwd: GCTTCAATGCTGTCTGGAGTC, rev: CTTGGAGGCCTGGCACATC); SLC51A (Bio-Rad, CustomPrimerPairDesalt200R, fwd: CAGATTGCTTGTT CGCCTCC, rev: ATTCGTGTCAGCACAGTCATTAG); and SLC51B (Bio-Rad, Custom Primer Pair Desalt 200R, fwd: CAGGAGCTGCTGGAAGAGAT, rev: GACCATGCTTATAATGACCACCA). SYBR Green fluorescent dye (Bio-Rad) was used for detection. Master mix-7.5 $\mu \mathrm{l}$ iQ SYBR Green Supermix (BioRad), $2.75 \mu \mathrm{l}$ RNAse-free water, and $0.75 \mu \mathrm{l}$ primer mix $(250 \mathrm{nM}$ final concentration)-was prepared in PCR tubes. Treated HepG2 cells or control CDNA, $4 \mu \mathrm{l}$ (1:10 dilution in nuclease-free water), were pipetted into 96-well plates and an $11 \mu \mathrm{l}$ master mix for each gene was added. The CDNA of pooled RNA was added to the master mix for each gene to create a reverse transcription negative control (RT-), no other template controls were included. PCR conditions (CFX96 Touch Real-Time PCR Detection System; Bio-Rad) were initially $95^{\circ} \mathrm{C}, 3 \mathrm{~min} ; 40$ cycles, $95^{\circ} \mathrm{C}, 15$ $\mathrm{s}$, and $60^{\circ} \mathrm{C}, 30 \mathrm{~s}$; melt curve with $60^{\circ} \mathrm{C}$ to $95^{\circ} \mathrm{C}$ (an increase of $0.5^{\circ} \mathrm{C} / 5 \mathrm{~s}$ ). The data were normalized to the expression of $\beta$-actin and relative gene expression was assessed using the $\Delta \Delta \mathrm{Cq}$ method [24]. $\Delta \Delta \mathrm{Cq}$-values were normalized to $400 \mu \mathrm{M}$ DMSO. All measurements were performed in duplicates from three independent experimental replicates.

\section{Fluorescence microscopy}

HepG2 cells were incubated with $600 \mu \mathrm{M}$ CDCA, GCDCA, UDCA, or $60 \mu \mathrm{M}$ GW4064 for $24 \mathrm{~h}$. Cells were fixed with ice-cold ethanol $(5 \mathrm{~min})$, washed twice with PBS ( $\mathrm{pH} 7.2)$, and stained with an Alexa Fluor 546 conjugated TF antibody (sc-374441 AF546, Santa Cruz Biotechnology) (1:100 in 0.1\% BSA, $30 \mathrm{~min})$. Then, cells were washed again with PBS and stained with $4^{\prime}, 6-$ diamidino-2-phenylindole (DAPI) $(1 \mu \mathrm{g} / \mathrm{ml}, 10 \mathrm{~min})$. Finally, cells were washed twice with PBS (pH 7.2) and evaluated via fluorescence microscopy.

\section{Flow cytometry analysis}

HepG2 cells were incubated with individual BA or GW4064 for $24 \mathrm{~h}$ and harvested using Accutase (Sigma; $5 \mathrm{~min}$, room temperature). Cells were centrifuged, resuspended $\left(10^{6}\right.$ cells $\left./ \mathrm{ml}\right)$ in Annexin binding buffer (BD Pharmingen, San Diego, CA), and stained with fluorescein isothiocyanate conjugated Annexin V (BD Pharmingen) and propidium iodide (Pl; Thermo Fisher Scientific). Cells were analyzed within $1 \mathrm{~h}$ using a Cytoflex $\mathrm{S}$ flow cytometer (Beckman Coulter, Brea, CA).

\section{Statistics}

Data obtained at different BA concentrations were tested against a vehicle with ANOVA and Dunnett's posthoc test using IBM SPSS Statistics 24.0 (SPSS Inc, Chicago, IL). $P$-values $<0.05$ were considered statistically significant. Data are presented as mean \pm standard deviation.

\section{RESULTS}

\section{Cell viability and cytotoxicity}

MTT testing revealed intact cell viability even at quite high BA concentrations throughout all performed experiments (Fig. 1C/ Fig. 3B). GCDCA and UDCA did not impair HepG2 cell viability in concentrations up to $1500 \mu \mathrm{M}$. CDCA caused a significant decrease in cell viability at concentrations $>1000 \mu \mathrm{M}$ (Fig. 1C). With GW4064 cell viability remained unimpaired up to $60 \mu \mathrm{M}$ and dropped at $100 \mu \mathrm{M}$ (Fig. 1D).

The LDH-Cytotoxicity Assay showed no observable LDH release from HepG2 cells after $24 \mathrm{~h}$ with BA concentrations up to $600 \mu \mathrm{M}$ (Fig. 1E). A minor increase in $\mathrm{LDH}$ release was observed at quite high GW4064 concentrations (100 $\mu$ M) (Fig. 1F).

\section{TF activity assay}

In HepG2 cells, TF activity was highest with $400 \mu \mathrm{M}$ and $600 \mu \mathrm{M}$ CDCA after $24 \mathrm{~h}(400 \mu \mathrm{M}: 44.2 \pm 34.8 \mathrm{pM} \mathrm{FXa/min} ; 600 \mu \mathrm{M}: 820 \pm$ $337 \mathrm{pM} \quad \mathrm{FXa} / \mathrm{min}$; vehicle: $10.3 \pm 9.5 \mathrm{pM} \mathrm{FXa} / \mathrm{min} ; \quad p<0.001$ ) (Fig. 1A). TF activity increased slightly with $100 \mu \mathrm{M}$ and $200 \mu \mathrm{M}$ CDCA after $72 \mathrm{~h}(100 \mu \mathrm{M}: 16.3 \pm 5.8 \mathrm{pM} \mathrm{FXa} / \mathrm{min} ; 200 \mu \mathrm{M}: 11.6 \pm$ $4.7 \mathrm{pM} \mathrm{FXa} / \mathrm{min}$; vehicle: $5.9 \pm 3.1 \mathrm{pM} \mathrm{FXa} / \mathrm{min} ; p<0.05)$; with higher concentrations of CDCA, it rose further at both $48 \mathrm{~h}$ and 72 h (Supplementary Fig. 1A). With higher CDCA concentrations, TF activity had already increased at $15 \mathrm{~min}$ (Supplementary Fig. 2A). In HepG2 cells, GCDCA did not induce TF activity at any setting, and UDCA induced an increase in TF activity only at the highest concentration after $24 \mathrm{~h}(600 \mu \mathrm{M}: 52.9 \pm 1.3 \mathrm{pM}$ FXa/min; vehicle: $14.5 \pm 1.2 \mathrm{pM} \mathrm{FXa/min} ; p<0.001$ ) (Fig. $1 \mathrm{~A}$ ).

The synthetic agonist GW4064 induced TF activity in a dosedependent manner after $24 \mathrm{~h}$ (Fig. 1B). A significant change in TF activity was already observable at lower concentrations (5 $\mu \mathrm{M}$ : $40.2 \pm 18.4 \mathrm{pM}$ FXa/min; vehicle: $12.6 \pm 4.3 \mathrm{pM} \mathrm{FXa/min).} \mathrm{Cell}$ viability was not impaired at the concentrations of GW4064 employed (Fig. 1D).

No increase in TF activity was observed with CDCA after $24 \mathrm{~h}$ when cells were incubated with the FXR antagonist DY 268 (10 $\mu \mathrm{M})$ (Fig. 2A). TF activity after exposure to GW4064 for $24 \mathrm{~h}$ was markedly reduced in presence of DY 268 (Fig. 2C). Neither CDCA/ GW4064 nor DY268 affected cell viability in the employed concentration range (Fig. 2B/D).

In our confirmation experiments with primary human hepatocytes, TF activity increased slightly after exposure to $100 \mu \mathrm{M}$ and $200 \mu \mathrm{M}$ CDCA for $24 \mathrm{~h}(100 \mu \mathrm{M}: 2.3 \pm 0.4 \mathrm{pM}$ FXa/min; $200 \mu \mathrm{M}: 2.7$ $\pm 1.1 \mathrm{pM} \mathrm{FXa} / \mathrm{min}$; vehicle: $1.1 \pm 0.7 \mathrm{pM} \mathrm{FXa} / \mathrm{min} ; p<0.05)$ and rose significantly with $400 \mu \mathrm{M} \mathrm{CDCA}(5.2 \pm 0.5 \mathrm{pM} \mathrm{FXa/min;} p<0.001)$. Notably, in contrast to HepG2 cells, TF activity was increased after exposure to GCDCA at all applied concentrations for $24 \mathrm{~h}$ and even higher than with CDCA $(100 \mu \mathrm{M}: 12.9 \pm 8.9 \mathrm{pM}$ FXa/min; 200 $\mu \mathrm{M}: 13.1 \pm 6.4 \mathrm{pM} \mathrm{FXa/min;} 400 \mu \mathrm{M}: 14.4 \pm 8.5 \mathrm{pM} \mathrm{FXa/min}$; vehicle: $3.1 \pm 1.5 \mathrm{pM}$ FXa/min; $p<0.001$; Fig. $3 \mathrm{~A}$ ).

\section{Thrombin generation assay}

Of all parameters derivable from the thrombin trace, the lag time until onset of thrombin generation was most influenced by preincubation of HepG2 cells with BA. A dose-dependent lag time reduction and a corresponding increase in ETP and peak thrombin generation were observable with CDCA and GW4064 (Fig. 4A/D/E, Table $1 ; p<0.001$ ) but not with UDCA or GCDCA (Fig. $4 \mathrm{~B} / \mathrm{C} / \mathrm{E}$, Table 1, $p<0.001)$. Interestingly, UDCA at the lowest concentration $(100 \mu \mathrm{M})$ reproducibly prolonged the lag time to a small extent (Fig. 4C/E). 
A

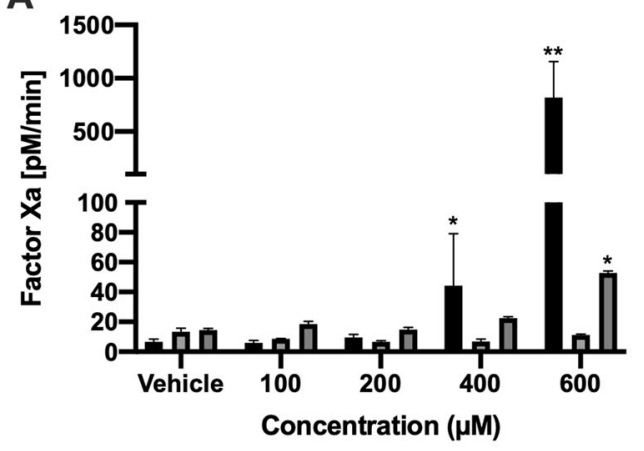

C

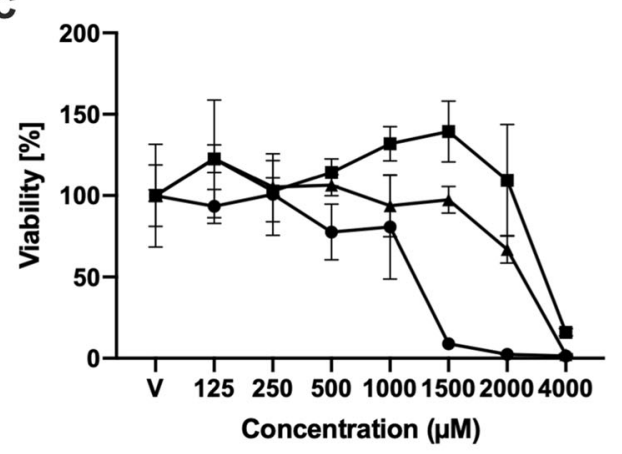

E

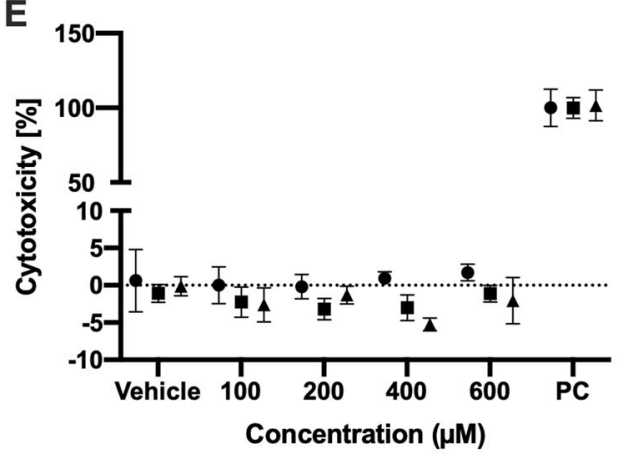

B

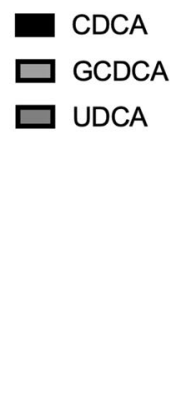

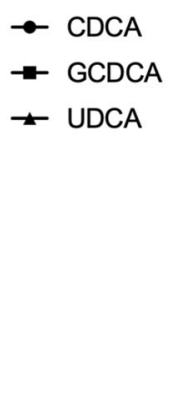

D

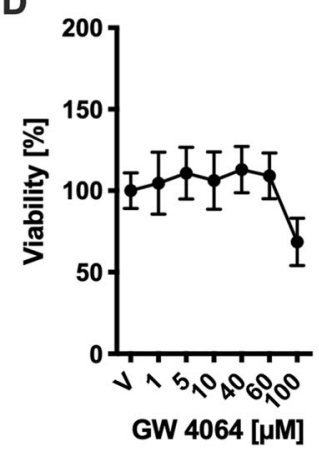

F

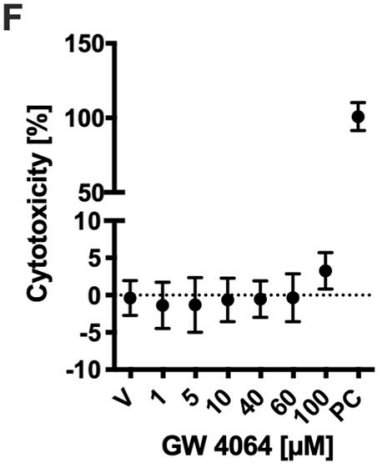

Fig. 1 Tissue factor (TF) activity, cell viability, and cytotoxicity after incubation with various bile acids or GW4064. TF activity was assessed via the generation of coagulation factor Xa (FXa). A HepG2 cells were incubated with CDCA, GCDCA, and UCDA (100-600 $\mu$ M) for $24 \mathrm{~h}$. B HepG2 cells were incubated with GW4064 (1-40 $\mu \mathrm{M})$ for $24 \mathrm{~h}$. Dimethyl sulfoxide was used as the vehicle. Data are expressed as mean \pm SD $(N=6)$. C MTT assay showed the viability of the cells at the concentrations used in the TF activity assay. HepG2 cells were incubated with CDCA, GCDCA, and UDCA (125-4000 $\mu \mathrm{M})$ for $24 \mathrm{~h}$. D HepG2 cells were incubated with GW4064 (1-100 $\mu \mathrm{M})$ for $24 \mathrm{~h}$. Data are presented as \% viability and expressed as mean $\pm S D(N=6)$. E/F Cytotoxicity assay showed no observable LDH release with CDCA, GCDCA, UDCA, and GW4064 after $24 \mathrm{~h}$. Data are presented as \% cytotoxicity and expressed as mean \pm SD $(N=6)$. PC positive control consisting of lysed cells. ${ }^{*} p<0.05$ for a difference from a vehicle; ${ }^{* *} p<0.001$ for a difference from a vehicle.

\section{TF protein levels}

Western blot experiments showed no dose-dependent upregulation of TF protein levels after exposure of HepG2 cells to CDCA, GCDCA, UDCA, or GW4064 for $24 \mathrm{~h}$ in all concentrations employed for TF activity measurements (Fig. 5A-D). Densitometric analysis of blot bands normalized to GAPDH showed no significant change in TF protein expression levels (Fig. 5E). Equivalently, fluorescence microscopy images of stained HepG2 cells showed no upregulation or redistribution of TF after exposure to CDCA, GCDCA, UDCA $(600 \mu \mathrm{M})$, or GW4064 $(60 \mu \mathrm{M})$ for $24 \mathrm{~h}$ (Supplementary Fig. 3).

\section{Apoptosis markers}

Increased TF activity was detected in the absence of cell death and intact plasma membrane, denoted by positive MTT tests and no $\mathrm{LDH}$ release (Fig. 1/2/3, Supplementary Fig. 1/2). Caspase 3 activity was not increased after exposure to CDCA, GCDCA, UDCA
(100-600 $\mu \mathrm{M})$, or GW4064 (1-60 $\mu \mathrm{M})$ for $24 \mathrm{~h}$. On the other hand, incubation with staurosporine $(2-4 \mu \mathrm{M})$ induced a substantial surge in caspase 3 activity (Fig. 6). Using flow cytometry no significant Annexin $\mathrm{V}$ binding attributable to apoptosis was observable in any population, even at quite high BA concentrations $(600 \mu \mathrm{M})$, (Supplementary Fig. 4).

\section{qPCR analysis of FXR activation and TF expression}

Changes in mRNA levels of FXR activation markers, as well as TF expression levels after exposure to $200 \mu \mathrm{M}$ BA or $20 \mu \mathrm{M}$ GW4064, were evaluated after $12 \mathrm{~h}$ and $24 \mathrm{~h}$ (Fig. 7). The FXR target genes SLC51A and SLC51B were substantially upregulated compared with the DMSO control when cells were preincubated with CDCA or GW4064, while no effect was observed with GCDCA or UDCA.

The FXR target gene NROB2 was minimally upregulated compared with the DMSO control with CDCA or GW4064 after 
A

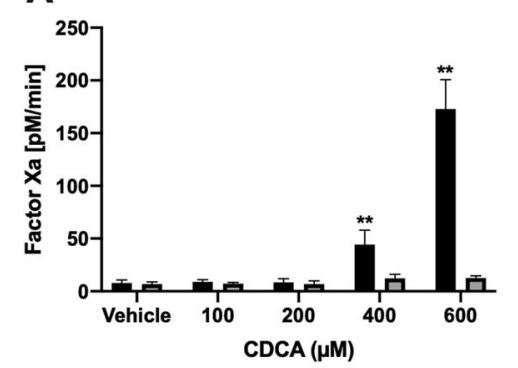

C

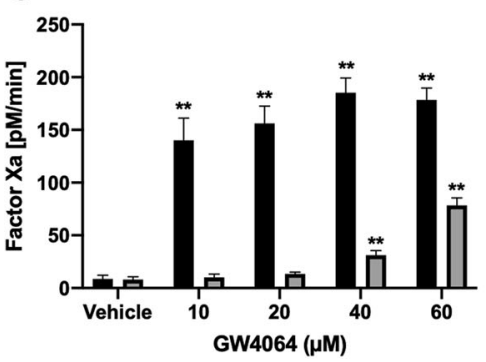

B

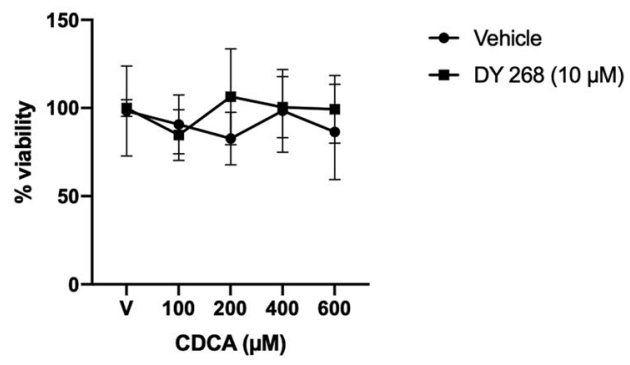

D

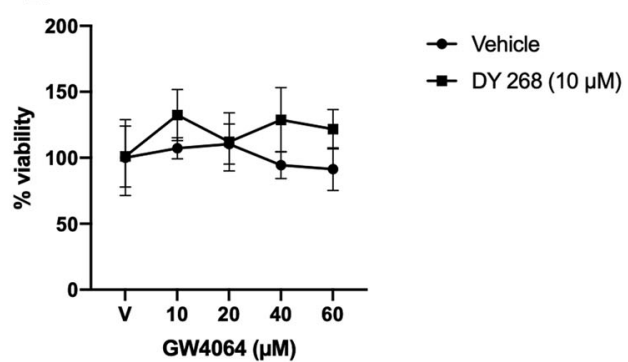

Fig. 2 Reduced TF activity in presence of the FXR antagonist DY 268. TF activity was assessed via generation of coagulation factor Xa (FXa) after exposure of HepG2 cells to (A) CDCA $(100-600 \mu \mathrm{M})$ or (C) GW4064 (10-60 $\mu \mathrm{M})$ for $24 \mathrm{~h}$ with and without the addition of the FXR inhibitor DY $268(N=3)$. B/D MTT assay showed unimpaired viability. ${ }^{* *} p<0.001$ for the difference from the vehicle.

A

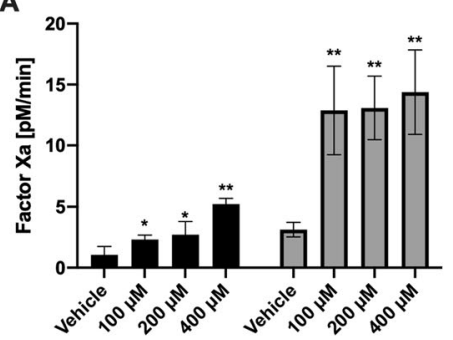

B

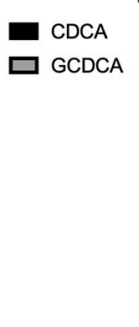

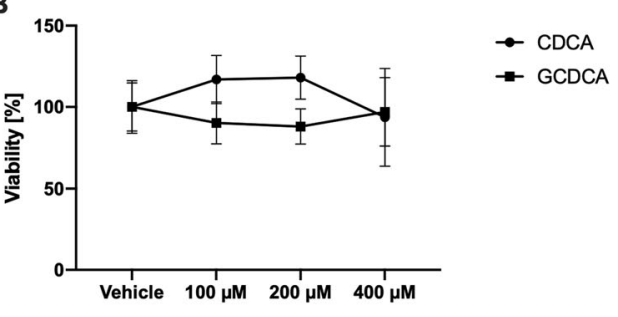

Fig. 3 Increase of TF activity in primary human hepatocytes after incubation with bile acids. A TF activity was assessed via the generation of coagulation factor Xa (FXa). Primary human hepatocytes were incubated with 100, 200, or $400 \mu \mathrm{M}$ of CDCA or GCDCA for $24 \mathrm{~h}$. Dimethyl sulfoxide was used as a vehicle. Data are expressed as mean \pm SD $(N=6)$. B MTT assay showed the viability of the cells at the concentrations used in the TF activity assay. Data are presented as \% viability of the cells and expressed as mean \pm SD $(N=6)$. ${ }^{*} p<0.05$ for the difference from vehicle; ${ }^{* *} p<0.001$ for the difference from the vehicle.

$12 \mathrm{~h}$ of incubation but not after $24 \mathrm{~h}$. No effect was observed with GCDCA or UDCA. None of the employed BA or GW4064 triggered upregulation of TF at any concentration after any interval (Supplementary Table 1).

\section{DISCUSSION}

Besides their other metabolic functions, BA is involved in TF activation [12]. In mouse models of cholestatic liver injury, local activation of hemostatic pathways leads to recruitment of inflammatory cells and activation of hepatic stellate cells, which fosters liver fibrosis and contributes to disease progression $[9,13,25]$. These models show elevated levels of BA in hepatocytes coincident with activated coagulation and platelets in correlation with disease severity $[13,25,26]$.

We investigated the potential of various BA to induce TF-activity and thrombin generation in HepG2 cells and found that TF activity is enhanced after incubation with CDCA but not with GCDCA or UDCA. In accordance with enhanced TF activity, we observed changes in thrombin generation (shortened lag time and increased ETP) after incubation with CDCA but not with GCDCA or UDCA. We also performed confirmation experiments in primary human hepatocytes. Overall TF activity was lower with primary human hepatocytes than with HepG2 cells, due to lower cell numbers which required tailoring of experimental procedures. Nevertheless, we found enhanced TF activity after incubation with CDCA as well as with GCDCA. With the latter, we found significant dose-dependent effects starting at lower concentrations $(100 \mu \mathrm{M})$. Thus, compared to HepG2 cells, primary hepatocytes show a higher sensitivity to BA exposure, leading to increased TF activity at lower BA concentrations. Based on these findings, we conclude that in a cholestatic setting elevated BA might indeed trigger TF activity in vivo, which is in line with increased thrombinantithrombin complexes and intrahepatic fibrin(ogen) deposits observed in mice after bile duct ligation [12].

The BA concentrations which induced TF activity in primary hepatocytes correspond to total serum concentrations frequently observed in patients with PSC. While unconjugated BA constitutes the minority of the $\mathrm{BA}$ pool in these patients, individual conjugated BA such as GCDCA can reach concentrations above $100 \mu \mathrm{M}$ [27]. Serum BA levels in PBC patients are usually lower than those of PSC patients [28]. However, in all cholestatic 

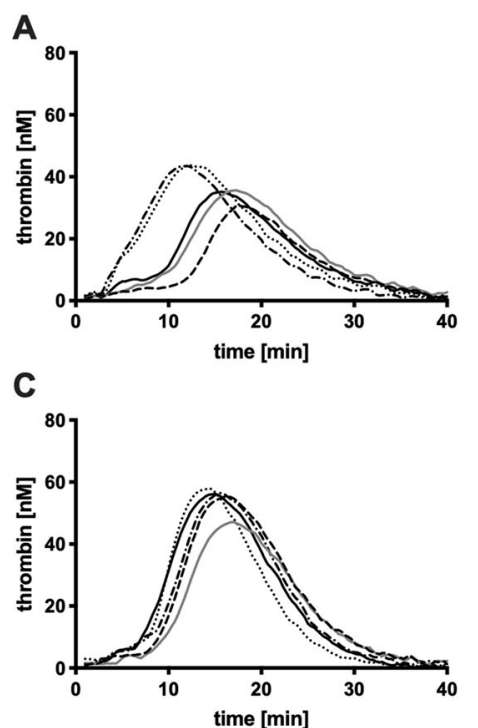

E

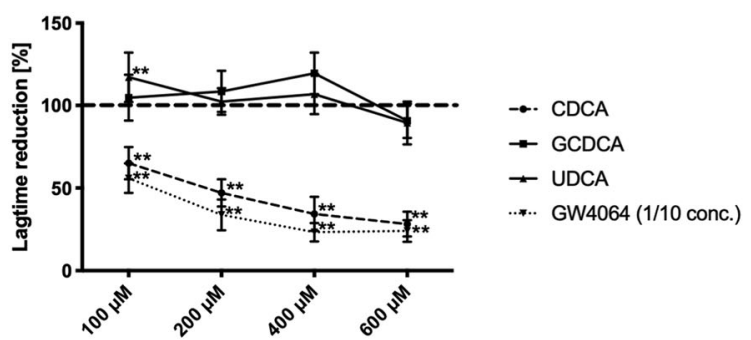

B

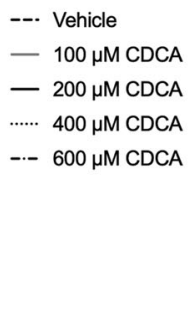

$-\cdot$ Vehicle
$-100 \mu \mathrm{M}$ UDCA

- $200 \mu \mathrm{M}$ UDCA

...... $400 \mu \mathrm{M}$ UDCA

-.- $600 \mu \mathrm{M}$ UDCA

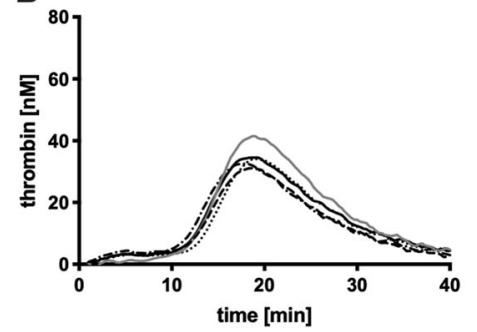

--. Vehicle

- $100 \mu \mathrm{M}$ GCDCA

- $200 \mu \mathrm{M}$ GCDCA

…. $400 \mu \mathrm{M}$ GCDCA

-.- $600 \mu \mathrm{M}$ GCDCA

--. Vehicle

..... $40 \mu \mathrm{M}$ GW4064

-.- $60 \mu \mathrm{M}$ GW4064
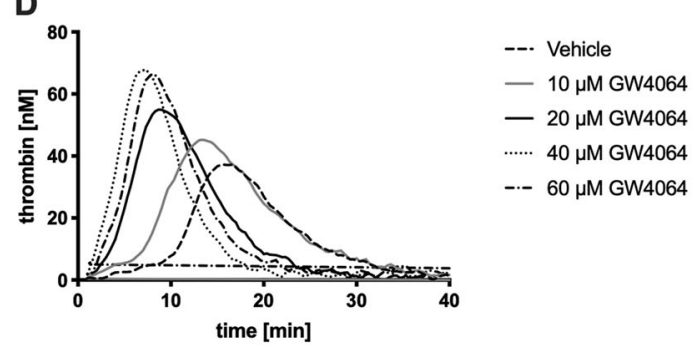

$$
\text { . }
$$

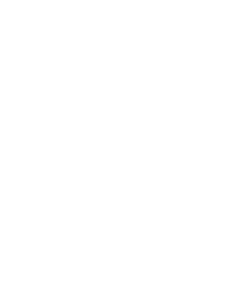

Fig. 4 Representative thrombin generation traces after incubating HepG2 cells with BA. The ability of a sample to generate thrombin was evaluated with respect to the time preceding the thrombin burst (lag time) and the total amount of thrombin activity (endogenous thrombin potential), which was assessed as the area under the curve. HepG2 cells were incubated with 100, 200, 400, or 600 $\mu \mathrm{M}$ of (A) CDCA, (B) GCDCA, (C) UDCA, or (D) 1, 5, 10, or $40 \mu \mathrm{M}$ of GW4064. Dimethyl sulfoxide was used as the vehicle. Measurements were carried out after the addition of corn trypsin inhibitor to block contact activation of coagulation. $\mathbf{E}$ Lag time reduction/prolongation in \%, induced by various bile acids in different concentrations. Data are expressed as mean $\pm \mathrm{SD}(N=9)$. ${ }^{* *} p<0.01$ for the difference from the vehicle.

disorders obstruction of bile flow can lead to substantially higher BA levels within the liver parenchyma than in the plasmatic spill over, resulting in intrahepatic BA concentrations equivalent to those employed in our experiments [29].

We then investigated if variation in the ability of BA to induce TF activity depends on their amphiphilic properties or on their ability to activate intracellular FXR. We used GW4064, a potent FXR agonist without the steroid structure of BA. GW4064 and BA induced TF activity equally well, pointing to an FXR dependent mechanism. We then investigated the ability of different $B A$ and GW4064 to induce intracellular FXR signaling in HepG2 cells by determining expression levels of FXR target genes NROB2, $S L C 51 A$, and SLC51B using GPCR. Interestingly, the ability of different BA and GW4064 to induce FXR signaling in HepG2 cells correlated with their ability to trigger TF activity. CDCA and GW4064 induced substantial overexpression of FXR target genes while GCDCA and UDCA showed no effect. These observations indicate that enhanced TF activity in HepG2 cells after incubation with CDCA and GW4064 is not a phenomenon resulting only from the interaction of $B A$ with the cell membrane. CDCA and GW4064 potentially trigger TF activity and thrombin generation via intracellular signaling that involves FXR. This notion is supported by the absence of CDCA mediated TF activity when FXR signaling was blocked by the potent antagonist DY 264. Equivalently, GW4064 mediated TF activity was markedly reduced in presence of DY 264. An increase in TF activity was observed at quite high GW4064 concentrations
$(40-60 \mu M)$, which is most likely attributable to the substantially higher FXR activating potential of GW4064 compared to CDCA. FXR activation thus might be a key feature in the activation of local coagulation processes.

Interestingly, on assessment as an FXR target gene, F3 was not upregulated in quantitative PCR, which was confirmed by unaltered TF protein levels observable in Western blot analysis and fluorescence microscopy. These data argue for TF decryption and not for TF upregulation causing the rise in TF activity.

Theoretically, the TF activity observed could be a non-specific feature of cell death and apoptosis caused by BA overload. We used BA concentrations far below the critical micellar concentration [30] thus excluding cell damage by saponification. According to our MTT data, cells were viable, and according to the LDH assay plasma membranes were uncompromised at all employed concentrations of BA and GW4064.

Cell membrane changes, especially loss of lipid asymmetry, are features associated with apoptosis [31] which may be responsible for TF activation. We tested for caspase 3 activity and phosphatidylserine expression to investigate if apoptosis was associated with the observed increase in TF activity. No rise in caspase 3 activity was detected in HepG2 cells with any employed concentrations of BA or GW4064. Likewise, no increase in phosphatidylserine expression was observed by flow cytometry. We, therefore, conclude that the increase in TF activity is not caused by apoptotic effects and alterations in the plasma membrane. 
Table 1. Parameters of thrombin generation curves after incubation of HepG2 cells with various bile acids or GW4064 $(N=6)$.

\begin{tabular}{|c|c|c|c|}
\hline & Lag time [min] & Peak height [nM] & ETP [nM*min] \\
\hline \multicolumn{4}{|l|}{ CDCA } \\
\hline Vehicle & $11.00 \pm 1.05$ & $30.72 \pm 4.03$ & $432.1 \pm 89.5$ \\
\hline $100 \mu \mathrm{M}$ & $7.16 \pm 1.07^{* *}$ & $35.83 \pm 5.69$ & $556.0 \pm 76.1^{*}$ \\
\hline $200 \mu \mathrm{M}$ & $5.17 \pm 0.91^{* *}$ & $36.31 \pm 5.61^{*}$ & $530.9 \pm 69.3^{*}$ \\
\hline $400 \mu \mathrm{M}$ & $3.78 \pm 1.14^{* *}$ & $43.84 \pm 7,92^{* *}$ & $640.6 \pm 91.4^{* *}$ \\
\hline $600 \mu \mathrm{M}$ & $3.10 \pm 0.82^{* *}$ & $44.55 \pm 5.41^{* *}$ & $631.4 \pm 82.4^{* *}$ \\
\hline \multicolumn{4}{|l|}{ GCDCA } \\
\hline Vehicle & $11.04 \pm 1.09$ & $34.51 \pm 4.19$ & $548.8 \pm 71.3$ \\
\hline $100 \mu \mathrm{M}$ & $11.51 \pm 1.53$ & $38.18 \pm 6.93$ & $539.1 \pm 81.5$ \\
\hline $200 \mu \mathrm{M}$ & $11.92 \pm 1.22$ & $35.02 \pm 5.05$ & $571.9 \pm 85.4$ \\
\hline $400 \mu \mathrm{M}$ & $11.68 \pm 1.23$ & $34.13 \pm 4.72$ & $587.3 \pm 69.2$ \\
\hline $600 \mu \mathrm{M}$ & $8.86 \pm 1.01$ & $33.27 \pm 5.28$ & $535.8 \pm 93.6$ \\
\hline \multicolumn{4}{|l|}{ UDCA } \\
\hline Vehicle & $8.76 \pm 0,74$ & $55.44 \pm 7.10$ & $545.9 \pm 82.4$ \\
\hline $100 \mu \mathrm{M}$ & $10.26 \pm 1.32^{*}$ & $47.08 \pm 6.89^{*}$ & $503.4 \pm 72.4$ \\
\hline $200 \mu \mathrm{M}$ & $8.97 \pm 0.70$ & $56.62 \pm 7.32$ & $581.7 \pm 83.0$ \\
\hline $400 \mu \mathrm{M}$ & $9.36 \pm 1.06$ & $57.73 \pm 5.95$ & $577.3 \pm 65.8$ \\
\hline $600 \mu \mathrm{M}$ & $7.83 \pm 1.13$ & $57.08 \pm 6.13$ & $586.9 \pm 92.3$ \\
\hline \multicolumn{4}{|l|}{ GW4064 } \\
\hline Vehicle & $10.55 \pm 1.13$ & $37.97 \pm 5.33$ & $503.7 \pm 70.1$ \\
\hline $10 \mu \mathrm{M}$ & $5.91 \pm 0.94^{* *}$ & $46.61 \pm 5.59^{*}$ & $589.4 \pm 76.7^{*}$ \\
\hline $20 \mu \mathrm{M}$ & $3.56 \pm 0.98^{* *}$ & $55.47 \pm 6.01^{* *}$ & $611.7 \pm 79.4^{* *}$ \\
\hline $40 \mu \mathrm{M}$ & $2.45 \pm 0.59^{* *}$ & $69.60 \pm 7.13^{* *}$ & $637.3 \pm 80.2^{* *}$ \\
\hline $60 \mu \mathrm{M}$ & $2.54 \pm 0.69^{* *}$ & $67.32 \pm 7.84^{* *}$ & $629.5 \pm 76.7^{* *}$ \\
\hline
\end{tabular}

Our findings complement a recent study in which BA was demonstrated to accelerate TF/FVIla complex activation directly by acting as cofactors [12]. Our results vary from those in that study which reported an effect with GCDCA but not with GW4064 in primary mouse hepatocytes after $30 \mathrm{~min}$ of incubation. These differences can most likely be ascribed to differences in methodologies. In contrast to primary hepatocytes, HepG2 cells do not express sodium taurocholate cotransporting polypeptide (NTCP) [32], which regulates hepatocellular uptake of conjugated BA [33]. Hence, GCDCA cannot enter HepG2 cells which are reflected by the absence of FXR activation. To substantiate this hypothesis, we performed control experiments with primary human hepatocytes expressing NTCP, and indeed found dosedependent effects with GCDCA as well.

Differences in the effect of GW4064 are most likely attributable to different incubation times. Our study exposed cells for $24 \mathrm{~h}$ rather than $30 \mathrm{~min}$. BA-induced TF activation increases with time and takes several hours to be detectable. Since in our study BA had been removed from cells before TF activity and thrombin generation was measured, the observed effects cannot be attributable to the proposed cofactor activity of BA for TF/FVIla and suggest long-lasting rather than short-term effects.

We speculate that in a cholestatic setting prolonged FXR overstimulation eventually leads to changes in intracellular signaling that result in TF activation. The absence of an acute response is conceivably a protective mechanism, as short-term BAmediated FXR activation without TF activation is required for physiological regulation of $B A$ synthesis.

We observed no rise in TF activity or FXR activation with UDCA at low and intermediate concentrations $(<600 \mu \mathrm{M})$, even though,

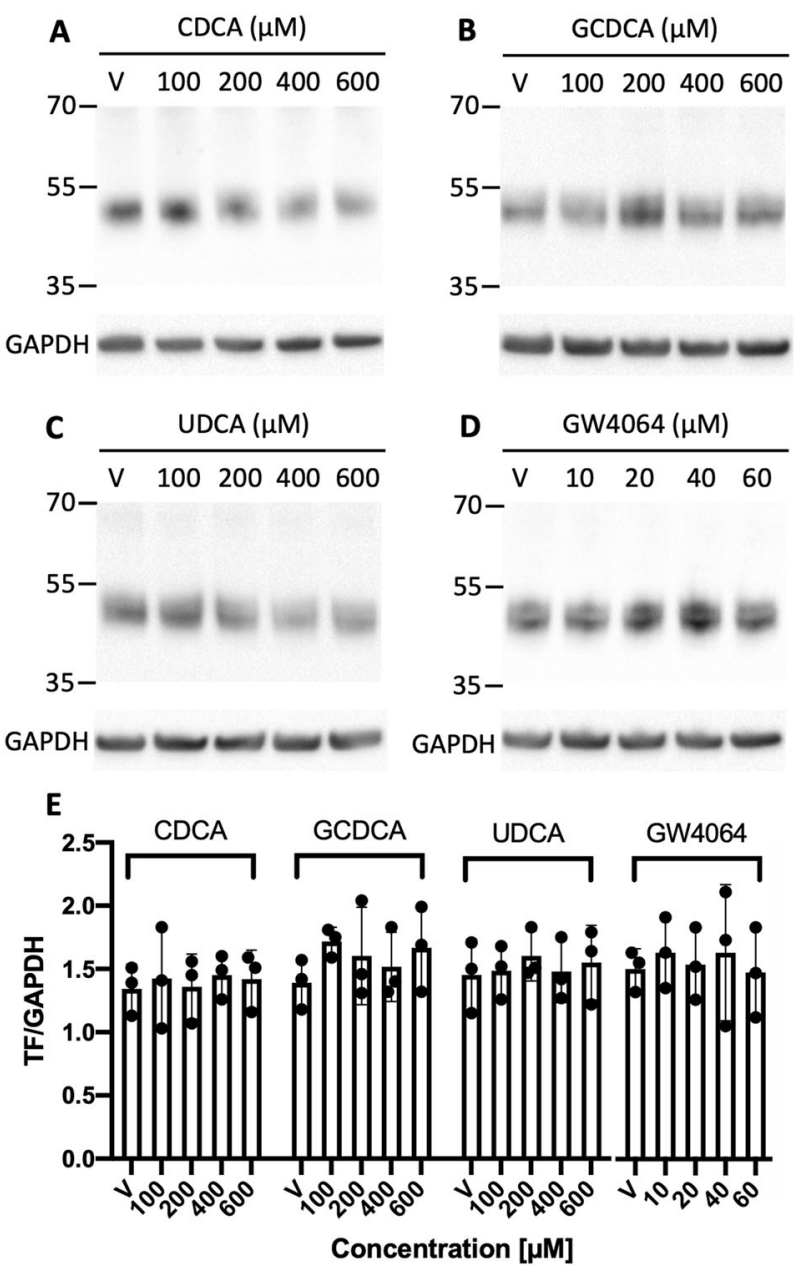

Fig. 5 Protein levels of TF after exposure to BA or GW4064. A-D Representative Western blots of TF after incubation of HepG2 cells with CDCA, GCDCA, UDCA $(100-600 \mu \mathrm{M})$, or GW4064 (10-60 $\mu \mathrm{M})$. Dimethyl sulfoxide was used as the vehicle. GAPDH was used as a control. E Densitometric analysis with normalization to GAPDH from three independent experimental replicates.

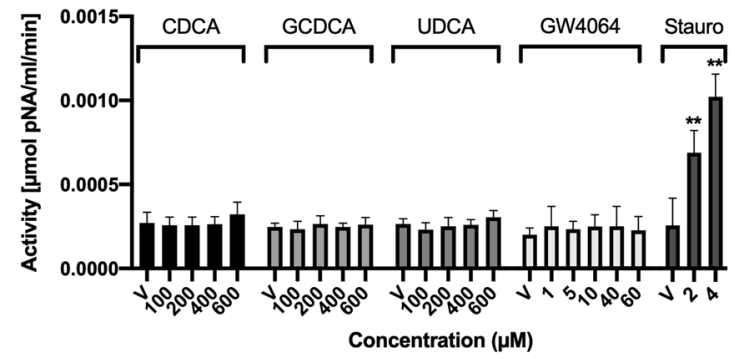

Fig. 6 Caspase 3 activity in HepG2 cells after exposure to BA, GW4064, or staurosporine. Caspase 3 activity was determined with a colorimetric assay based on p-nitroaniline (pNA) release from a peptide substrate (Ac-DEVD-pNA). HepG2 cells were incubated with CDCA, GCDCA, and UDCA $(100-600 \mu \mathrm{M})$, GW4064 (1-60 $\mu \mathrm{M})$, or staurosporine $(2-4 \mu \mathrm{M})$ for $24 \mathrm{~h}$. Dimethyl sulfoxide was used as a vehicle. Data are expressed as mean \pm SD $(N=6)$. ${ }^{* *} p<0.01$ for a difference from the vehicle.

in contrast to GCDCA, UDCA is an unconjugated BA and thus potentially able to enter HepG2 cells without active transport by NTCP. UDCA is a commonly used therapeutic agent in cholestatic liver disease. It slows down disease progression, confers shortterm improvement in values for serum biomarkers of hepatobiliary 


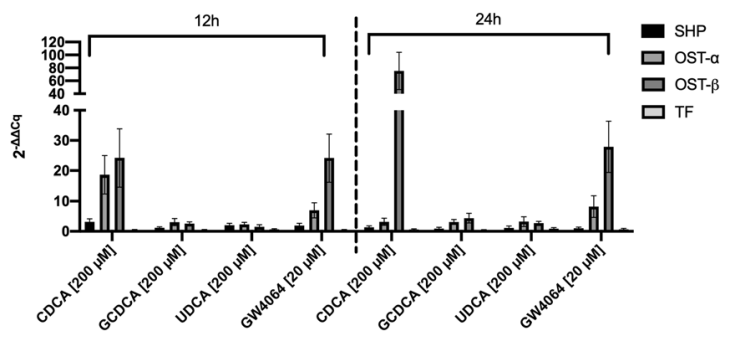

Fig. 7 Upregulation of FXR targets via chenodeoxycholic acid (CDCA). HepG2 cells were incubated with $200 \mu \mathrm{M}$ of chenodeoxycholic acid (CDCA) and with $20 \mu \mathrm{M}$ of GW4064 for $12 \mathrm{~h}$ or $24 \mathrm{~h}$. SHP, OST- $\alpha$, OST- $\beta$, and tissue factor (TF) were used as primers, with SHP, OST- $\alpha$, and OST- $\beta$ as known FXR targets. Data were normalized using the expression of $\beta$-actin and relative gene expression was assessed using the $\Delta \Delta \mathrm{Cq}$ method. $\Delta \Delta \mathrm{Cq}$-values were normalized to dimethyl sulfoxide. Data are expressed as mean fold change $\left(2^{-\Delta \Delta \mathrm{Cq}}\right)(N=2)$.

injury, and in moderate doses has a favorable safety profile [34]. UDCA is less hydrophobic than CDCA and GCDCA, and on the molecular level, UDCA is regarded as at least a weak FXR antagonist explaining the absence of FXR activation and TF decryption in our experiments [35].

In our TF activity measurements, we added rFVIla to increase sensitivity for low levels of active TF. Preliminary experiments with exogenous negatively charged phospholipids showed no factor $X$ conversion with our assay in absence of TF. Furthermore, unaltered Annexin binding in our flow cytometry experiments precludes changes in lipid composition as a direct trigger for factor $\mathrm{X}$ conversion.

In our thrombin generation experiments, no exogenous TF was added, and contact activation was completely suppressed by the addition of corn trypsin inhibitor leaving endogenous TF activity the sole trigger for thrombin generation. We conclude that the observed effects in our TF activity and thrombin generation experiments are indeed caused by the procoagulant activity of decrypted TF.

Limitations of these in vitro studies include the use of a purified chemical environment for our cells and plasma for our CAT analyses. Although the space of Disse permits physiological contact of hepatocytes with plasma proteins, we could not entirely simulate the natural environment of the liver parenchyma.

We conclude that long-term exposure of hepatocytes to nontoxic BA such as CDCA can induce TF decryption and upregulate TF-induced thrombin generation. These effects correlate with the activation of FXR pathways and occur independently of apoptotic mechanisms.

\section{DATA AVAILABILITY}

The datasets used and/or analyzed during the current study are available from the corresponding author on reasonable request.

\section{REFERENCES}

1. Theiler-Schwetz V, Zaufel A, Schlager H, Obermayer-Pietsch B, Fickert P, Zollner G. Bile acids and glucocorticoid metabolism in health and disease. Biochim Biophys Acta. 2019;1865:243-51.

2. Trauner M, Claudel T, Fickert P, Moustafa T, Wagner M. Bile acids as regulators of hepatic lipid and glucose metabolism. Dig Dis. 2010;28:220-4.

3. Lefebvre P, Cariou B, Lien F, Kuipers F, Staels B. Role of bile acids and bile acid receptors in metabolic regulation. Physiol Rev. 2009;89:147-91.

4. Saeed A, Hoekstra M, Hoeke MO, Heegsma J, Faber KN. The interrelationship between bile acid and vitamin A homeostasis. Biochim Biophys Acta. 2017;1862:496-512.

5. Hegyi P, Maléth J, Walters JR, Hofmann AF, Keely SJ. Guts and gall: bile acids in regulation of intestinal epithelial function in health and disease. Physiol Rev. 2018;98:1983-2023.
6. Gadaleta RM, van Mil SWC, Oldenburg B, Siersema PD, Klomp LWJ, van Erpecum $\mathrm{KJ}$. Bile acids and their nuclear receptor FXR: relevance for hepatobiliary and gastrointestinal disease. Biochim Biophys Acta. 2010;1801:683-92.

7. Makishima M, Okamoto AY, Repa JJ, Tu H, Learned RM, Luk A, et al. Identification of a nuclear receptor for bile acids. Science. 1999;284:1362-5.

8. Poisson J, Lemoinne S, Boulanger C, Durand F, Moreau R, Valla D, et al. Liver sinusoidal endothelial cells: Physiology and role in liver diseases. J Hepatol. 2017;66:212-27.

9. Nishio T, Hu R, Koyama Y, Liang S, Rosenthal SB, Yamamoto G, et al. Activated hepatic stellate cells and portal fibroblasts contribute to cholestatic liver fibrosis in MDR2 knockout mice. J Hepatol. 2019. https://doi.org/10.1016/j. jhep.2019.04.012

10. Keitel V, Dröge C, Häussinger D. Targeting FXR in cholestasis. Handb Exp Pharmacol. 2019;256:299-324.

11. Chascsa D, Carey EJ, Lindor KD. Old and new treatments for primary biliary cholangitis. Liver Int. 2017;37:490-9.

12. Baker KS, Kopec AK, Pant A, Poole LG, Cline-Fedewa H, Ivkovich D, et al. Direct amplification of tissue factor: factor Vlla procoagulant activity by bile acids drives intrahepatic coagulation. Arterioscler Thromb Vasc Biol. 2019;39:2038-48.

13. Sullivan BP, Weinreb $\mathrm{PH}$, Violette $\mathrm{SM}$, Luyendyk JP. The coagulation system contributes to $\mathrm{aV} \beta 6$ integrin expression and liver fibrosis induced by cholestasis. Am J Pathol. 2010;177:2837-49.

14. Pant A, Kopec AK, Luyendyk JP. Role of the blood coagulation cascade in hepatic fibrosis. Am J Physiol - Gastrointest Liver Physiol. 2018;315:G171-G176.

15. Poole LG, Pant A, Cline-Fedewa HM, Williams KJ, Copple BL, Palumbo JS, et al. Liver fibrosis is driven by protease-activated receptor- 1 expressed by hepatic stellate cells in experimental chronic liver injury. Res Pract Thromb Haemost. 2020: 906-17. https://doi.org/10.1002/rth2.12403

16. Kopec AK, Luyendyk JP. Role of Fibrin(ogen) In Progression Of Liver Disease: Guilt By Association? Semin Thromb Hemost. 2016;42:397-407.

17. Copple BL, Moulin F, Hanumegowda UM, Ganey PE, Roth RA. Thrombin and protease-activated receptor-1 agonists promote lipopolysaccharide-induced hepatocellular injury in perfused livers. J Pharmacol Exp Ther. 2003;305:417-25.

18. Rao LVM, Pendurthi UR. Regulation of tissue factor coagulant activity on cell surfaces. J Thromb Haemost. 2012;10:2242-53.

19. Chen VM, Hogg PJ. Encryption and decryption of tissue factor. J Thromb Haemost. 2013;11:277-84.

20. Kahn ML, Zheng YW, Huang W, Bigornia V, Zeng D, Moff S, et al. A dual thrombin receptor system for platelet activation. Nature. 1998;394:690-4.

21. Sullivan BP, Kopec AK, Joshi N, Cline H, Brown JA, Bishop SC, et al. Hepatocyte tissue factor activates the coagulation cascade in mice. Blood. 2013;121:1868-74.

22. Versteeg $\mathrm{HH}$, Ruf $\mathbf{W}$. Tissue factor coagulant function is enhanced by proteindisulfide isomerase independent of oxidoreductase activity. J Biol Chem. 2007;282:25416-24.

23. Haidl H, Zöhrer E, Pohl S, Leschnik B, Weiss EC, Gallistl S, et al. New insights into neonatal coagulation: normal clot formation despite lower intra-clot thrombin levels. Pediatr Res. 2019;86:719-24.

24. Pfaffl MW. A new mathematical model for relative quantification in real-time RTPCR. Nucleic Acids Res. 2001;29:45e-45.

25. Yoshida S, Ikenaga N, Liu SB, Peng ZW, Chung J, Sverdlov DY, et al. Extrahepatic platelet-derived growth factor- $\beta$, delivered by platelets, promotes activation of hepatic stellate cells and biliary fibrosis in mice. Gastroenterology. 2014;147:1378-92.

26. Joshi N, Kopec AK, O'Brien KM, Towery KL, Cline-Fedewa H, Williams KJ, et al. Coagulation-driven platelet activation reduces cholestatic liver injury and fibrosis in mice. J Thromb Haemost. 2015;13:57-71.

27. Mousa OY, Juran BD, McCauley BM, Vesterhus MN, Folseraas T, Turgeon CT, et al. Bile acid profiles in primary sclerosing cholangitis and their ability to predict hepatic decompensation. Hepatology. 2020: 0-2. https://doi.org/10.1002/ hep.31652

28. Poupon RE, Chrétien Y, Poupon R, Paumgartner G. Serum bile acids in primary biliary cirrhosis: Effect of ursodeoxycholic acid therapy. Hepatology. 1993;17:599-604.

29. Zhang $Y$, Hong J, Rockwell CE, Copple BL, Jaeschke $H$, Klaassen CD. Effect of bile duct ligation on bile acid composition. Liver Int. 2013;32:58-69.

30. Tamesue N, Juniper K. Concentrations of bile salts at the critical micellar concentration of human gall bladder bile. Gastroenterology. 1967;52:473-9.

31. Pyrshev KA, Klymchenko AS, Csúcs G, Demchenko AP. Apoptosis and eryptosis: striking differences on biomembrane level. Biochim Biophys Acta. 2018;1860:1362-71.

32. Boyer JL, Hagenbuch B, Ananthanarayanan M, Suchy F, Stieger B, Meier PJ. Phylogenic and ontogenic expression of hepatocellular bile acid transport. Proc Natl Acad Sci USA. 1993;90:435-8. 
33. Denson LA, Sturm E, Echevarria W, Zimmerman TL, Makishima M, Mangelsdorf DJ, et al. The orphan nuclear receptor, shp, mediates bile acid-induced inhibition of the rat bile acid transporter, ntcp. Gastroenterology. 2001;121:140-7.

34. Beuers $U$, Trauner $M$, Jansen $P$, Poupon R. New paradigms in the treatment of hepatic cholestasis: From UDCA to FXR, PXR and beyond. J Hepatol. 2015;62: S25-S37.

35. Mueller $M$, Thorell A, Claudel T, Jha P, Koefeler H, Lackner C, et al. Ursodeoxycholic acid exerts farnesoid $X$ receptor-antagonistic effects on bile acid and lipid metabolism in morbid obesity. J Hepatol. 2015;62:1398-404.

\section{ACKNOWLEDGEMENTS}

We thank A.S. Knisely for his comments on the manuscript.

\section{AUTHOR CONTRIBUTIONS}

$A S, J$, and MW performed study concept and design; TG, AS, KM, VA, JZ, HH, SG, and MW performed development of methodology and writing, review, and revision of the paper; TG, SP, TS, MT, NM, SH, and AS provided acquisition, analysis, and interpretation of data, and statistical analysis; KP provided technical and material support. All authors read and approved the final paper.

\section{FUNDING}

The authors received no specific funding for this work.

\section{CONFLICT OF INTEREST}

The authors declare no competing interests.

\section{ETHICAL APPROVAL}

This in vitro study did not require ethical approval.

\section{ADDITIONAL INFORMATION}

Supplementary information The online version contains supplementary material available at https://doi.org/10.1038/s41374-021-00628-z.

Correspondence and requests for materials should be addressed to A.S.

Reprints and permission information is available at http://www.nature.com/ reprints

Publisher's note Springer Nature remains neutral with regard to jurisdictional claims in published maps and institutional affiliations. 